\title{
The Effectiveness of Clinical Colloquium Established by the "Drawing Recall" Technique in University Counselling Services for Student Mental Health
}

\author{
Valeria Biasi' ${ }^{1}$ Paolo Bonaiuto² ${ }^{2}$ Nazarena Patrizi'1, James M. Levin ${ }^{3}$ \\ ${ }^{1}$ Department of Education, "Roma Tre" University, Rome, Italy \\ ${ }^{2}$ Faculty of Medicine and Psychology, "Sapienza" University of Rome, Rome, Italy \\ ${ }^{3}$ John Jay College, City University of New York, New York, USA \\ Email: valeria.biasi@romascuola.net, paolo.bonaiuto@uniroma1.it, jameslevin@msn.com
}

Received 11 April 2015; accepted 5 May 2015; published 8 May 2015

Copyright (C) 2015 by authors and Scientific Research Publishing Inc.

This work is licensed under the Creative Commons Attribution International License (CC BY). http://creativecommons.org/licenses/by/4.0/

(c) (i) Open Access

\section{Abstract}

An experimental assessment of the effectiveness of university counselling was conducted through the "Stress Drawing Recall" Technique applied before and after a clinical colloquium with 70 university students of both genders, aged 18 - 35 years, who had requested this service. Another 70 students waiting to undergo the colloquium were interviewed as a control group. Two parallel series of drawings depicting personal stress situations were collected and, after evaluation by three expert judges in "double-blind" conditions, led to establishing five forms of development of the graphic language from the first to second drawing, defined as follows: a) distension, with a reduction in stress indicators and increase in comfort indicators; b) explicit representation of conflict resolution; c) appearance of new elements, with persisting conflict; $d$ ) increase in stress indicators; e) invariant or equivalent repetition of the stress drawing. Results showed that students who underwent the clinical colloquium (experimental group) changed their stress drawings mainly in the direction of distension and conflict resolution, while the control group had more invariant or equivalent repetition of the stress situation $\left(X_{4}^{2}=62.77 ; \mathrm{p}<0.001\right)$. The events depicted in the stress drawings were divided into three categories: a) limited short-term stressful situations due to mainly external agents; b) externally induced stressful situations with intense emotional resonance; c) wide-ranging long-lasting stressful situations with great involvement of the self. The participants were divided into: a) very anxious subjects; b) averagely anxious subjects; c) not very anxious subjects, on the basis of their scores on two questionnaires: the MPI (1959) and the STAI (1970). There is a correspondence between the subjects' level of conflict and extension of the depicted stress. This confirms the usefulness of the Stress Drawing Recall Technique in psychological 
counselling.

Keywords

Assessment, Clinical Colloquium, Counselling Service, Drawing Recall Technique, Personality Test

\section{Introduction. The Effectiveness of the Clinical Colloquium for the Assessment of University Counselling Services}

A useful way to assess the effectiveness of psychological counselling consists of analyzing the actual clinical colloquium, particularly the one of psychodynamic orientations. To this end, we consider it useful to focus on the characteristics of the clinical colloquium and on the many emotional, motivational and cognitive dynamics affecting the subject and the interviewer him/herself—-the therapist or counsellor-according to peculiar modalities.

From the therapist's standpoint, there is continuous data gathering-a quasi systematic or thorough investigation of the verbal and non-verbal information emerging from the factual clinical context, the so-called "here and now", and from the context we can call "virtual", concerning the reconstruction of past events. The reconstruction operation appears closely connected to links, completions and adjustments which underline the presence of a "plausible" construction of the reality experienced, adopting the narrative construct alongside the concept of explanation of the occurrence. By focusing on the internal dynamics experienced by the therapist or counsellordynamics which can be traced thanks to self-analysis and supervised analysis of counter-transfer-we can establish the deep conflictual nuclei and the defence mechanisms primarily used by the subject under examination.

There is also continual recourse to the process of simultaneous verification of the interpretative hypotheses under construction, which are thus better defined and restructured in a creative manner. This verification is conducted through feedback based on the information emerging very frequently from the patient's mimicry, posture and general attitude, from the words used as well as the silences, from the emotional intensity that language can have as well as overt or covert moments of opposition to communication. This cognitive activity can be likened to intraperceptive reasoning in terms of inferences, following von Helmhlotz [1]; that is to say, those perceptual experiences resulting from a weighted, intraperceptive calculation of the information collected.

A determining factor for the psychological analysis is surely the therapist's or counsellor's ability to grasp which interpretative hypothesis appears fitting and which interpretative cues should instead be excluded, suspended or put on hold for further confirmation.

The therapist or counsellor intuitively knows the most productive moment to introduce an interpretation during the colloquium, on the basis of the patient's level of attention and emotional involvement. If deep conflicts are reactivated in the communication, there is generally an increase in the main "negative" emotions such as anxiety, anger and sorrow. The need for congruity also substantially increases, with the resulting need for explanation [2]. In these affective conditions, the subject is plausibly more receptive to new contents which, although complex or partly obscure, trigger cognitive restructuring processes with short- and long-term effects.

In general, the therapist or counsellor "tries" several hypotheses - which will then be completed and enriched with the patient's contribution - and evaluates, on the spur of the moment, the distensive or alarming effects that can clarify the advanced interpretation or not. We recall, in any case, that in the relevant literature [3], when the explanation is clarifying (fitting), it may go either in the direction of distension or of alarm (depending on whether we are referring to an evident conflict or to a latent and masked one).

Sometimes, the new explicative contents can be left suspended, like a burden that is present but still not assimilable: the fact that its presence is accepted may make for a possible reprocessing in the future. Another element of feedback may also be given by the patient's net opposition to interpretation: this shows a defensive attitude and can thus signal that the therapist has—albeit incautiously—hit the mark.

Using the patient's emotional and cognitive reactions regarding the new contents proposed, which we can call "therapeutic schemas", it is possible to adapt them, specify them and deepen them. The quality of the interpretation appears determinant, that is, the structure of the explanation offered, constructed and shared during the clinical colloquium. 
Applying the scientific paradigm of experiential research to the complex and dynamic subject matter of the clinical colloquium inevitably brings with it a reductionist vision of the psychological processes involved. It is still useful at the scientific level to try to systemize or define what general factors come into play as independent or dependent variables in the psychotherapeutic process and-perhaps in a reduced manner-in psychological counselling. A second step could be that of establishing the specific factors of the different therapeutic orientations inspiring the interview technique.

By using the phenomenological approach we can isolate the various components dynamically present in the period of the clinical meeting. As a preliminary, the main variables identified are the following: a) psychological conflicts; b) psychological defences; c) the interpersonal relationship (the quality of the transfer and countertransfer); d) relaxation; e) suggestion; f) explanation, that is, the interpretation or narrative provided and/or coconstructed; g) cognitive reprocessing; h) emotional restructuring; i) "restitution”; j) detachment.

The first six components above appear to generally act as independent variables within the colloquium, while the others can be studied mainly as affects of the previous ones, and particularly of the kind of explanation provided. Cognitive reprocessing, emotional restructuring and "restitution", even in terms of compensation, and detachment, are usually considered as dependent variables; but they can also create effects in their turn [4].

The nature of psychological conflicts and the personal ability to resolve and/or cope are central aspects for the successful outcome of a psychotherapy or of a psychological counselling action.

A condition acting both when initially welcoming the patient and also later on is the subject's degree of relaxation. This can be induced directly or indirectly by the therapist through body language, tone of voice, the use of open questions, an empathic attitude, smartness of appearance and in clothing, the choice of furnishing and thus of the setting. A good level of relaxation is generally functional to the recall of conflictual material: muscular relaxation in a comfortable armchair or, in more orthodox fashion, on the classic couch, facilitates the temporary easing of tension, particularly when accompanied by non-verbal cues of a comfortable environment and signals, sometimes subliminal ones, of an accepting and listening attitude on the part of the therapist or counsellor. By lessening the level of conflict of the moment it becomes relatively easier for the patient to deal with the painful themes which may also appear bizarre and initially incomprehensible, as is often the case with memories, dreams or symptoms in general.

This kind of setting may basically be given a regressive, infantile or playful feature suitable to a call for affection and comprehension that is partly comparable-in the expressive qualities-to the calls for care and assistance made by a child who has hurt himself and to the reparatory response provided by the mother. To limit this collusive transfer involvement there are certain elements which stimulate a relative detachment, such as a certain tidiness and order in the room, certain rules of behaviour to be respected (e.g., where to sit, at what distance from the analyst, how long to stay for, etc.) [5].

According to the theory of conflict overload as a stress factor, a high degree of negative emotions make people less tolerant of novelties, incongruities and oddities [6]: qualities common to the conflictual material that one tries to bring to consciousness during the psychotherapy or psychological counselling session. Relaxation facilitates incongruity tolerance by opening the road to a more harmonious activation of explanation processes and responsibility attribution processes thereby predisposing the acceptance and processing of the interpretations provided and also enabling an active search for repressed contents and their narrative reconstruction, not too far removed from the creative act.

To facilitate the acquisition of explicative contents there are also suggestive dynamics facilitated by the idealization of the figure of the therapist or counsellor. This reinforces the reparatory role of a therapeutic narrative geared to attenuating the internal conflicts.

As reported in the experimental studies mentioned [3], in order to have measurable effects, the explanation must be expressed in coordinated and causal terms, and not stop at a mere description of the phenomenon observed. At a therapeutic level, however, a descriptive narrative can still appear reassuring since it can facilitate cathartic effects and recovery of the impression of control on the stressful agents. But the underlying feature of a fitting explanation provided is the ability to clarify the cause-effect relations among the variables of the phenomenon under study.

Bolton and Hill [7], amongst others, have dealt with the causal role of meaning attribution and the transformation of meaning during psychotherapy, showing some convergences between psychoanalytical contents and recent cognitive studies. One effect of the interpretation or attribution of meanings (causal and otherwise) consists of the cognitive reprocessing which also includes any changes in the levels of reality forming the basis for 
the perception of the reprocessed conflictual materials. Another effect is the emotional restructuring and start of the concrete and symbolic phenomena of the so-called "restitution", with aspects of recognition, progressive independence and then detachment. It is also possible to identify the nature and role of the verbal and non-verbal components of the session. Both the nature of the language used (such as the choice of vocabulary and syntax) and the non-verbal components, such as posture, mimicry, gestures, intonation, pauses, silences etc., and even the expressive qualities of the setting, the furnishings, light and sounds, and the passing of time add meanings that can come into the interpretative processes.

In our view, examining the effectiveness of the clinical colloquium with suitable tools is one of the most reliable indicators for assessing the effectiveness of university counselling services.

\section{The "Drawing Recall” Technique of Life Stress or Comfort Experiences: Previous Studies}

Biasi and Bonaiuto [8] [9] have performed experiments with adults who are asked to remember stressful or comfortable situations they have been in and to represent them in drawings. In the obtained drawings, characteristics of pictorial language (e.g. consisting of shapes of represented surfaces, presence or absence of colour, its scarcity or abundance, distribution, tonality, saturation, etc.) play a meaningful role. It is possible to study the relationships of pictorial language with other psychological variables. Moreover, the obtained drawings show very different levels of aesthetic quality when evaluated by independent judges and experts. An interesting question arises: whether there are meaningful relations between the emotions activated during the recollection and drawing activity, and the aesthetic value of the obtained pictorial image.

According to the experimental setting, the subject sits at a table with light pieces of drawing cardboard (32 $\times$ $24 \mathrm{~cm}$ ), a black pencil, an eraser, a black pen, thirty-six coloured pastels, and thirty-six coloured felt-tip pens. The subjects are young adults (19 - 39 years of age) treated individually and including both genders. Each person is asked to represent their own individual stressful or relaxing real-life experiences. Each drawing session lasts 20 minutes. In either case, if there is enough time, the subject is asked to imagine and represent another situation of the same type.

In the first case (stress) the instructions, given orally to the subject, are as follows:

"Now try to imagine and focus on a personal, particularly stressful, anxiety arousing, troubling and unpleasant situation. It can be a past experience or a present one, that you have felt in this way. Try to represent this experience with the materials here at your disposal. Do it freely, as you are able to, using whatever you wish...”

One of the main topics represented is urban congested traffic. People also draw car accidents, arguments in the family, broken relationships, examinations, feeling isolated, illness, or death of relatives. Sometimes, they represent stress in symbolic or abstract ways: a black sun, blots, straight and interrupted segments, etc. Generally, these drawings are in black and white.

In the opposite treatment, other subjects are asked to recall “.... a personal, particularly relaxing, comfortable, pleasant and enjoyable situation...” The remaining instructions are as above: "It can be a past experience or a present one, that you have felt in this way. Try to represent this experience with the materials here at your disposal. Do it freely, as you are able to, using whatever you wish, etc.”.

In comfort drawings the main topics are the contemplation of natural landscapes, flowers, trees, animals, the sea, etc. Also, they draw doing successful sport activities; or resting with favourite books, or listening to music; or having social or intimate relationships, etc. Colours are fully represented, including coloured contours, shadings, polychromies and other peculiarities. Shapes become rounded, lines are more continuous, drawn surfaces are more extended and show many details; and other specific aspects are represented.

Biasi and Bonaiuto fully examined the opposite techniques with many hundreds of participants and the data collected show that the psychological effects of these drawing recalling procedures are quite remarkable, considering two orders of consequences, as is explained below.

\subsection{Assessing Emotional States}

This non-intrusive procedure of drawing recollections of personal events induces very effective short term (reversible) states of stress or, respectively, comfort. Achievement of the programmed emotional states and the intensity of the main activated emotions, motivations and impressions are checked through the use of pre- and post-treatment Self-Appraisal Scales. 
Influences upon affective, cognitive and decisional processes are very similar to those observed with classical, more demanding and invasive techniques of stress or relaxation [2] [10].

Pre-post-treatment differences in scores pertaining to each emotion (anxiety, anger, sadness) as measured by the Self-Appraisal Scales show that stress produces a significant increase of these emotions while comfort drawings lead to a reduction.

There are important effects also at a motivational level: an increase in Aggressiveness, the need for Orderly Knowledge and for Body Movement, in stress conditions; and a complementary decrease in these needs in comfort conditions.

Factor analysis conducted on the data collected with the aforesaid Scales by Biasi, Bonaiuto and Giannini [10], showed that the stress condition exalts the adherence and communicative relevance of the affective states experienced. Main component analysis with Oblimin rotation, carried out on the scores obtained at peak stress, yielded three factors hypothesised as typically "negative" emotions: Anxiety, Anger and Sadness, each of which group together four relevant items, with saturations ranging from 0.50 to 0.95 . The values of the correlations between the three factors (from 0.55 to 0.49 ) are such to support the discriminating validity also enabling the grouping within the super ordinate factor "Negative Emotions).

As regards motivations, there are, as already mentioned, changes after stress treatment with respect to the need for Aggression, Body Movement and Cognitive Congruency. Each of the three motivations groups together three relevant items with saturations ranging from 0.50 to about 0.90 .

In our view, the emotional and motivational behaviours found have an original adaptive meaning, of affective and energetic mobilisation in the face of danger, threat or any enemy: anxiety and anger would reasonably accompany the increase in the need for movement, according to the primitive reactions of fight or flee. Sadness constitutes the effect of compromise between demands for aggression and legal constraints to venting one's tension. Finally, the increase in the need for cognitive congruence, which is expressed in the need for explanations, consistency and meanings, orients towards being able to understand the causes of problems in order to solve them as quickly as possible and to prevent them in the future.

In comfort conditions there is a natural relaxation that is also useful for suitable energy saving and recovery in view of future commitments.

These effects are identical to those obtained with classical experimental treatments, where we had subjects solving difficult logical problems under social pressure in the stress condition; or performing progressive muscular relaxation with guided imagery in a quiet darkened setting, in the comfort situation.

\subsection{Assessing Pictorial Languages}

Considering the pictorial language used in the obtained drawings, Biasi \& Bonaiuto [8] and Bonaiuto, Giannini and Biasi [11] applied fifteen pairs of bipolar indicators able to differentiate the images used in the two contrasting types of drawings, when independent examiners systematically evaluated their perceptual properties (colours, shapes, contours, structures, dispositions, style of execution, etc.).

The pictorial languages used in stress or comfort drawings appear clearly opposite, and this is confirmed when the judges, working methodologically in double blind conditions, systematically evaluated the drawing properties and peculiarities.

When recollecting stressful situations, as we have said, subjects, on average, use a large quantity of straight lines, angular surfaces, black contours, black and white representations (without colours).

When chromatic colours are present in stress drawings, preference is given to: black or, in any case, achromatic contours, dull colours, cold colours, alarming colours, extreme contrasts and conflicting colours, fragmented and less extended coloured areas.

Together with the larger number of straight lines, angular surfaces, simplification and executive hurry, colour inhibition or its selection and use appear expressive of conflict, and the selected aspects express negative emotions, aggression, defences, and avoidance of feelings.

For example, because chromatic colour, in general, is connected to the world of emotions, colour avoidance and denial appear as a display of defence against pain, suffering and trouble in dealing with stress, and especially distress. Hurry, speed and violence in colouring also express reluctance in experiencing, recognizing and staying in contact with one's own emotions during stress recollection; and also these energetic gestures revealed by static depictions directly express aggression and rigidity, which are two main effects of stress on motivational 
and cognitive levels.

On the other hand, when recollecting comfort situations, subjects mainly used: coloured contours (instead of achromatic contours), bright and warm colours, gradations, playful and reassuring colours, uniform and more extended coloured areas, together with curved and continuous lines, circular surfaces, rich details, executive accuracy, etc. The types of colours selected and used express attempts to solve and avoid conflict. Also, they express positive emotions, well accepted needs, pleasure and prolonged contact with inner feelings.

The expression of meanings appropriate to the contrasting concepts of stress or comfort, through the use of shapes and colours in drawing personal stressful or relaxing situations, appears based on the concurrence of different principles and mechanisms.

One is the tendency to reach a similarity between the attributes of shape and colour, on the one hand, and the attributes of the phenomenal ego, on the other, when it is affected by the typical emotional states of stress or comfort. This concept is related to the general principle of expression through isomorphism [12]. For this reason, for example, dissonant colours are preferred to express conflict, together with the fragmented and less extended coloured areas, and the speedy and nervous action tracks.

Moreover, there are rules generally accepted in communication based on shape and colour: because of the above-mentioned principle and because of those rules, it is almost automatic, for example, that the use of alarming colours, such as violet, black, dark blue, olive green indicates stress. On the other hand, playful and reassuring colours, such as pink, light green, yellow, orange, light blue and white, indicate comfort [13].

It is possible to check these relations by examining shapes and colours in pictorial practice, and especially in cartoons, in illustrated narratives, or in buildings and architectural structures.

Moreover, among the general principles and psychological mechanisms we should again take into consideration the dynamics of avoidance-approaching with respect to unpleasant or pleasant emotional states, as we mentioned before, and as it is also confirmed by the literature on Rorschach [14] and other projective tests.

\section{An Experimental Demonstration of the Effectiveness of the Clinical Colloquium of Psychodynamic Orientation in University Counselling}

\subsection{Hypotheses}

We made an experimental assessment of the effects of the clinical colloquium by means of the "drawing recall" technique. Recalling and drawing personal really experienced situations of stress can have two different roles, resulting as an independent or dependent variable.

a) "Drawing Recall" as an independent variable.

The "drawing recall" technique is applied as an independent variable as a treatment for producing short-term stress or comfort states. Cascade effects have been measured on amply described affective, cognitive and decisional processes [2] [10] [15].

b) "Drawing Recall” as a dependent variable.

The "stress drawing" is very interesting also as a dependent variable. In this case, we study its characteristics of content and style, and how they change after appropriate interventions. In this regard, a particular study proposed - immediately before the colloquium and opening it—conducting a single drawing focusing on a stressful situation really experienced by the subject. The instruction was reinforced by specifying that they should represent “... A situation that is very stressful for you, which you can then talk about". The task lasted a few minutes. After the clinical colloquium of 50 minutes the subject was asked to make a second drawing focusing on the same situation as before, as the subject wished to depict it at that particular moment:

"I would like you to represent the same situation that you find very stressful, worrying, anxiety-generating, unpleasant, which you depicted before: as you feel it now, spontaneously, with the materials you have available. You can use whatever you wish”.

\subsection{Procedure, Tools and Participants}

So far, the drawings produced individually before and after the colloquium has been gathered from 70 participants who had requested a short psychotherapy (the participants had varying degrees of emotional conflict; young adults of both genders, aged 18 - 35 years). To these drawings were added the ones of another 70 subjects who constituted a control group, still of patients awaiting psychotherapy, accurately balanced with regard to the 
first group. With the control group, between the first and second drawing session there was simply a 50 minute gap of normal daily life (reading, walking, chatting with friends etc.), while the colloquium itself was postponed to another appointment. On the whole, two parallel series of drawings were collected of personal stress situations from a total of 140 subjects. The participants were also asked to compile two psychodiagnostic questionnaires: the MPI by Eysenck [16] and the STAI of Spielberger, Gorsuch \& Lushene [16].

\subsection{Results}

Thanks to the evaluations of two expert judges in "double blind" conditions, five different forms of development of graphic language were distinguished in the subjects examined, from the first to second drawing. The five forms as defined as follows:

a) Distension, that is, a reduction in stress indicators and increase in comfort indicators;

b) Explicit representation of conflict resolution;

c) Appearance of new elements, with persistence and stability of the conflict, even in the restructuring of the depicted scene;

d) Increase in stress indicators;

e) Invariant or equivalent repetition of the stress drawing.

Examining the frequency distribution of the aforesaid processes, we noted that the people who underwent the psychotherapy session (experimental group) changed their stress drawings mainly in the direction of distension, and secondly towards conflict resolution. This was not the case with the control group, which instead showed an invariant or equivalent repetition of the stress drawing (Table 1).

Here are some examples of stress drawings which, as the work of the same subject each time, show the evolution of the graphic language in the direction of so-called "Distension", with the appearance of comfort indicators (Figure 1(a), Figure 1(b); Figure 2(a), Figure 2(b)); or in the direction of "Conflict resolution" (Figure 3(a), Figure 3(b)). Other pairs of drawings show a so-called "Invariant or equivalent repetition” (Figure 4(a), Figure 4(b); Figure 5(a), Figure 5(b)).

Table 1. Frequency distribution of the processes of graphic language evolution from the 1st to 2nd stress drawing in the experimental group and control group, out of a total of 140 participants. The difference between the two groups is highly significant $\left(X_{4}^{2}=62.77 ; \mathrm{p}<0.001\right)$.

\begin{tabular}{|c|c|c|c|c|c|}
\hline \multirow{2}{*}{$\begin{array}{l}\text { Groups } \\
N=140 \\
N=70\end{array}$} & \multicolumn{5}{|c|}{ Evolution of graphic language from 1st to 2nd stress drawing } \\
\hline & Distension & $\begin{array}{l}\text { Conflict } \\
\text { resolution }\end{array}$ & $\begin{array}{l}\text { Appearance of new elements } \\
\text { with persisting conflict }\end{array}$ & Increase in stress & $\begin{array}{l}\text { Invariant or equivalent } \\
\text { repetition }\end{array}$ \\
\hline $\begin{array}{l}\text { Experimental group } \\
\text { before and after the } \\
\text { clinical colloquium }\end{array}$ & 33 & 14 & 12 & 5 & 6 \\
\hline $\begin{array}{c}\text { Control group: } \\
\text { awaiting a } \\
\text { clinical colloquium }\end{array}$ & 5 & 3 & 7 & 6 & 49 \\
\hline
\end{tabular}

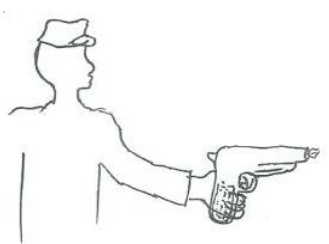

(a)

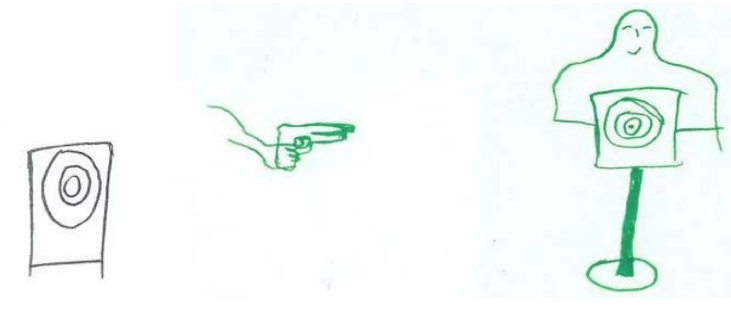

(b)

Figure 1. (a) (b) Example of "distension" in the shift from the first (a) to second (b) stress drawing. The first drawing focuses on the difficulties of military service. The later distension comes from the appearance of a bright light green colour instead of black and white, and the appearance of a smile among the features of the target. 


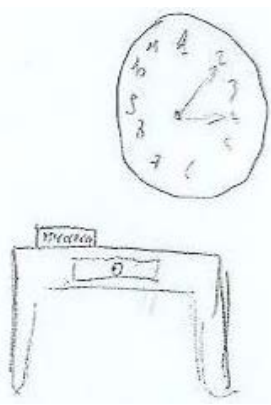

(a)

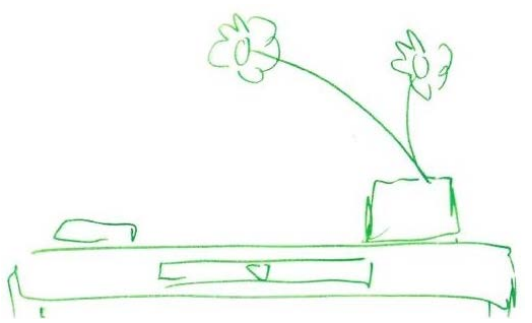

(b)

Figure 2. (a) (b) Example of "distension" in the shift from the first (a) to second (b) stress drawing. The first drawing focuses on the difficulties in studying in conditions of urgency. The later distension comes from the appearance of a bright light green colour instead of black and white, the disappearance of the goad of time, the amply expanded layout, and the addition of two large flowers on the desk.

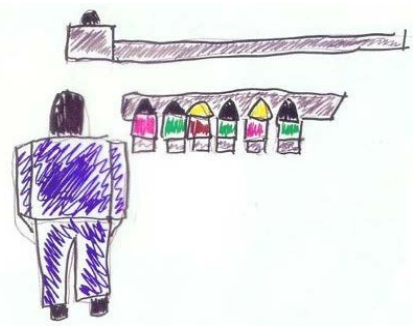

(a)

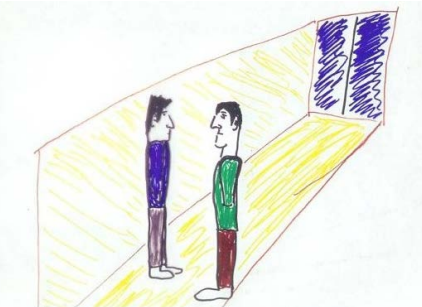

(b)

Figure 3. (a) (b) Example of "conflict resolution" in the shift from the first (a) to second (b) stress drawing. The first drawing focuses on a feeling of isolation and the difficulties of social relations. The conflict resolution is shown by the depiction of direct and friendly social contact, an expanded layout and changes in colour, with a particularly extensive use of yellow.

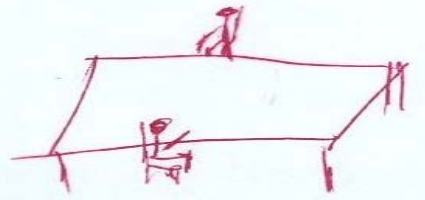

(a)

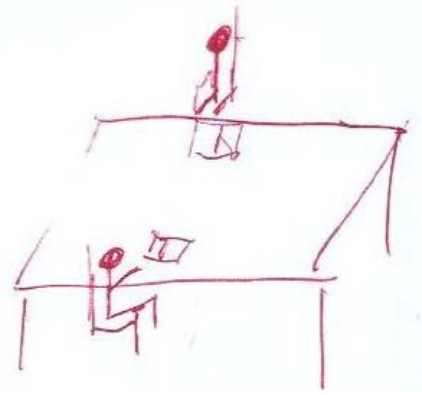

(b)

Figure 4. (a) (b) Example of "Invariant repetition" in the shift from the first (a) to second (b) stress drawing. The first drawing focuses on the representation of experienced stress during a university examination. The virtually invariant repetition appears evident when comparing the two drawings.

The events represented in the drawings of personal situations of stress can be listed and grouped according to various classification criteria. One criterion distinguishes the degree of extension and of involvement of the self, for which we have:

a) Limited externally-induced and generally inevitable short-term stressful situations: (i.e. bad weather, traffic, accidents, exams, military service, too many commitments, etc.); b) externally-induced stressful situations with 


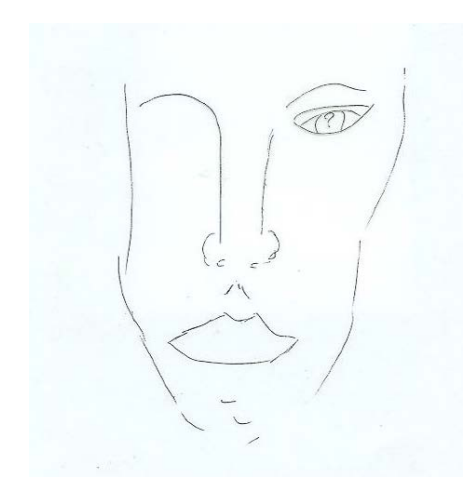

(a)

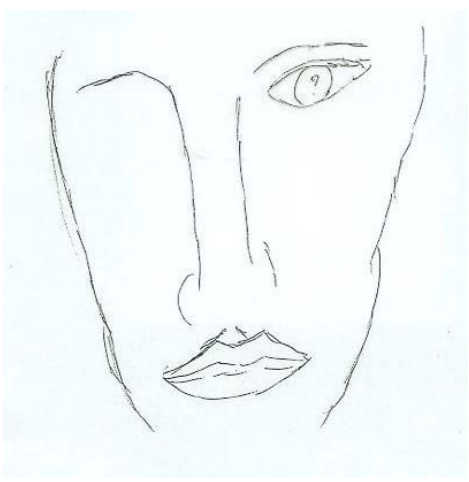

(b)

Figure 5. (a) (b) Example of "Invariant repetition in the shift from the first (a) to second (b) stress drawing. The first drawing focuses on the symbolic representation of stress as existential anxiety with regard to one's identity. The virtually invariant repetition appears evident when comparing the two drawings.

intense emotional resonance and connecting to personal contents; c) long-term stressful situations, broad extension and strong involvement of the Self (i.e., serious arguments in the family, social isolation and hostility, deep emotional conflicts, etc.).

The drawings made at the start of the colloquium or the waiting period, by the 140 participants, were assigned to each of the three aforesaid categories through a specific evaluation carried out by the two raters who assessed the whole material and reached an agreement with one another case by case under "blind" conditions.

Even the patients examined were distinguished into three categories depending on the levels of psychological conflict and thus the degrees of emotional tension, evaluated by means of two sensitive psychodiagnostic indicators: the $N$ score called "Neuroticism", ranging from 0 to 48 points, in the MPI questionnaire by Eysenck [16] and the $X$-2 score called "Trait anxiety", ranging from 20 to 80 points, in the STAI questionnaire by Spielberger, Gorsuch \& Lushene [17]. Both these tools, as we know, have been adapted to the Italian population and are widely used internationally. The questionnaires were compiled by patients a week before or after the drawing test.

The following categories were distinguished on the basis of the scores obtained:

1) Category A: Very anxious subjects: with $N>29$ and $X-2>49$.

2) Category B: Averagely anxious subjects: with $N$ between 20 and 29, $X-2$ between 40 and 49, or scores alternating between different categories.

3) Category C: Notvery anxious subjects: with $N<20$ and $X-2<40$.

The frequency distributions of the stressful situations depicted in the drawings differ progressively and congruently as a function of the patient's levels of conflict and anxiety, as shown in Table 2.

We can say that the stress drawing performed at the start of the colloquium by very anxious subjects predominately corresponds to "hot", broad, durable and very involving events and in which the Self is felt as strongly responsible for the stressful situation. This is the case, for example, of conflicts with regard to identity, difficult interpersonal relations, deep distress, experiences of isolation and social closure.

The decrease in levels of anxiety corresponds to a progressive substitution with emotionally "colder" events in which the stressful agents are mainly external, limited, often unavoidable or faced for clear practical reasons; such as being stuck in urban traffic, being in a queue at the post office and the like.

\section{Discussion and Conclusions}

This experimental study shows the effectiveness of the clinical colloquium of psychodynamic orientation in university counselling services, both with regard to typologies of stress experienced by university students and with regard to the characteristics of personality and thus the coping capacities developed. The general effect is in the direction of a significant emotional distension. The intervention obtained with the clinical colloquium also triggers complex cognitive reprocessing. 
Table 2. Absolute frequencies and percentages of the stressful situations depicted in the drawings opening the 1st colloquium, as a function of the three personality categories in which the 140 patients were divided (comparison of the three categories $X_{4}^{2}=20.13$; $\mathrm{p}$ 0.001; other comparisons A-C: $X_{2}^{2}=6.57$; $<0.05$ ).

\begin{tabular}{ccccc}
\hline & \multicolumn{3}{c}{ Stressful situations depicted in the 1st drawing } \\
\cline { 2 - 5 } $\begin{array}{c}\text { Personality } \\
\text { categories }\end{array}$ & $\begin{array}{c}\text { Mainly external } \\
\text { and limited } \\
\text { short-term agents }\end{array}$ & $\begin{array}{c}\text { Mainly external agents } \\
\text { but with intense } \\
\text { emotional resonance }\end{array}$ & $\begin{array}{c}\text { Long-term stressful } \\
\text { agents, great extension } \\
\text { and strong involvement } \\
\text { of the self }\end{array}$ & $\begin{array}{c}\text { Mean scores of conflict } \\
\text { and emotional } \\
\text { tension (indicators: } \\
N=\text { neuroticism; } \\
X-2=\text { trait anxiety) }\end{array}$ \\
$\begin{array}{c}\text { Category A. } \\
\text { Very anxious subjects } \\
\mathrm{n}=26(18.6 \%)\end{array}$ & $1(3.9 \%)$ & $3(11.5 \%)$ & $22(84.6 \%)$ & $N=35.9 ; X-2=58.7$ \\
$\begin{array}{c}\text { Category B. } \\
\text { Averagely anxious subjects } \\
\mathrm{n}=68 \text { (48.6\%) } \\
\text { Category C. }\end{array}$ & $12(17.7 \%)$ & $20(29.4 \%)$ & $36(52.9 \%)$ & $N=25.7 ; X-2=44.1$ \\
$\begin{array}{c}\text { Not very anxious subjects } \\
\mathrm{n}=46 \text { (32.8\%) }\end{array}$ & $17(37.0 \%)$ & $14(30.4 \%)$ & $15(32.6 \%)$ & $N=10.8 ; X-2=31.0$ \\
\hline
\end{tabular}

The international specialist literature shows the typology of psychological disorders currently affecting the university student population and underlines the need for, and usefulness of, university psychological counselling services, and the evaluation of their effectiveness.

As indicated by Hyun, Quinn, Madon and Lustig [18] examining mental health needs, knowledge, and utilization of counselling services among graduate students at a large university in western United States, almost half of graduate student respondents reported having had an emotional or stress-related problem over the past year.

The utilization of counselling services was positively associated with an index of depression symptoms especially with female students. Those students who had experienced a significant mental health event in the past year were significantly more likely to utilize counselling services. Findings suggest a need for increased attention to graduate student mental health needs.

Also Russell, Thomson \& Rosenthal [19] examined a large sample of international students attending an Australian metropolitan university and provided data concerning the use of university health and counselling services - their perceived need for help, resultant help-seeking, satisfaction with help given, explanations for not seeking help when in need, and variables that predicted help-seeking. Using, as criterion, the individual's perceived need for help, they found students were under-utilizing both health and counselling services. Those who did seek help evaluated their experiences positively.

Recently, Samuolis and Griffin [20] examined the prevalence of identity distress among college students and the degree to which participants may meet the DSM-IV classification for identity problems. In addition, the study examined the extent to which participants with high levels of identity distress report symptoms of depression and other symptoms of negative affect.

Findings indicated that $8.1 \%$ of the sample met the DSM-IV description for identity problems as assessed with the Identity Distress Survey. Those who met the criteria for identity problems reported significantly more loneliness, overwhelming anger, hopelessness and depression, compared with those without identity problems. The identity areas of long-term goals, friendships and career were more likely to be rated as causing severe distress and were more likely to be associated with specific negative affect symptoms.

In 2015 Biasi, Mallia, Menozzi \& Patrizi [21] conducted a study aimed at assessing different areas of individual adaptive and maladaptive functioning of university students in order to identify their main problematic areas and improving the quality of the university counselling service.

Two hundred and fifty female students aged 18 - 29 years, attending the first year of the Educational Sciences course, filled out the Italian version of the Achenbach Self Report (Achenbach \& Rescorla, 2003) questionnaire assessing five areas of adaptive functioning (i.e. Friends, Spouse/partner, Family, Job and Education), and eight areas of behavioural, emotional and social problems (i.e. Anxious/Depressed, Withdrawn, Somatic Complaints, Thought Problems, Attention Problems, Aggressive Behaviour, Rule-breaking Behaviour and Intrusive). Sociodemographic variables and past experience with psychological help services were also assessed. 
Results show that $26.0 \%$ of the students had asked for psychological help in the past. Moreover, these students reported higher scores in several problematic areas (i.e. Anxious/Depressed, Withdrawn, Somatic Complaints, Thought Problems, Attention Problems, Aggressive Behaviour) with respect to those who had never asked for psychological help. Results confirm the presence of adjustment problems in university students and the need to take into account the student's mental health by giving local university counselling services indications about the main problematic areas of their target population.

Finally, the utility of university counselling services is generally recognized in different contexts and countries; but for a scientific approach it is necessary to measure and detect the effects of these interventions. Indeed, we consider two main and interrelated effects: an effect on academic carrier and a psychological effect on the student's wellbeing and health.

With the experimental study presented here we underline the relevance of assessing the effectiveness of university counselling services, in particular, with the monitoring of the efficacy of the clinical colloquium, which is surely one of the most important and valuable tools in clinical psychology.

\section{References}

[1] von Helmholtz, H. (1856-1866) Handbuck der phisiologischen Optik. Voss, Leipzig.

[2] Bonaiuto, P., Biasi, V., Giannini, A.M., Bonaiuto, M. and Bartoli, G. (1992) Stress, Comfort and Self-Appraisal: A Panoramic Investigation of the Dynamics of Cognitive Processes. In: Forgays, D.G., Sosnowski, T. and Wrzesniewski, K., Eds., Anxiety: Recent Developments in Cognitive, Psychophysiological and Health Research, Hemisphere, Washington DC, 75-107.

[3] Bonaiuto, P., Biasi, V., Bonaiuto, G. and Giannini, A.M. (2011) A Description of Incongruous Architectures and Related Observations. In: Bonaiuto, M., Bonnes, M., Nenci, A.M. and Carrus, G., Eds., Urban Diversity-Environmental and Social Issues, Hogrefe, Göttingen, 109-121.

[4] Biasi, V. and Bonaiuto, P. (2012) The Scientific Contribution of the Clinical Method in Educational Research (Il portatoscientifico del metodocliniconelleapplicazioni educative: Uno studio di caso). Journal of Educational, Cultural and Psychological Studies, 6, 107-127. http://dx.doi.org/10.7358/ecps-2012-006-bias

[5] Saraval, A. (1988) La tecnicaclassica e la suaevoluzione. In: Semi, A.A. (a cura di), Trattato di Psicoanalisi. Volume Primo. Teoria e Tecnica, Cortina, Milano, 533-613.

[6] Biasi, V., Bonaiuto, P. and Levin, J. (2015) Relation between Stress Conditions, Uncertainty and Incongruity Intolerance, Rigidity and Mental Health: Experimental Demonstrations. Health, 7, 71-84. http://dx.doi.org/10.4236/health.2015.71009

[7] Bolton, D. and Hill, J. (1997) On the Causal Role of Meaning. In: Power, M. and Brewin, C.R., Eds., The Transformation of Meaning in Psychological Therapies, Wiley, New York, 15-31.

[8] Biasi, V. and Bonaiuto, P. (1997) Colour and the Experimental Representation of Stress and Comfort. In: Sivik, L., Ed., Colour \& Psychology, Scandinavian Colour Institute, Stockholm, 54-65.

[9] Biasi, V. and Bonaiuto, P. (2007) Stress or Comfort Drawings. A Technique for Activating and Evaluating Real Emotional States and for Detecting Emotional Meanings. In: Zammuner, V.L. and Galli, C., Eds., Giornata di Studio sulleEmozioni, Padova, 19 Novembre 2007, 66-69.

[10] Biasi, V., Bonaiuto, P. and Giannini, A.M. (2010) Measures of Emotional and Motivational Processes Activated by Stress or Comfort Conditions. Key Engineering Materials, 437, 540-544. http://dx.doi.org/10.4028/www.scientific.net/KEM.437.540

[11] Bonaiuto, P., Giannini, A.M. and Biasi, V. (2003) Perception Theories and the Environmental Experience. In: Bonnes, M., Lee, T. and Bonaiuto, M., Eds., Psychological Theories for Environmental Issues, Ashgate, Aldershot, 95-136.

[12] Arnheim, R. (1949) The Gestalt Theory of Expression. Psychological Review, 56, 156-171. http://dx.doi.org/10.1037/h0061787

[13] Biasi, V., Bonaiuto, P. and Levin, J. (2014) The "Colour Family Drawing Test”: A Comparison between Children of "Harmonious” or "Very Conflictual Families”. Psychology, 5, 2099-2108. http://dx.doi.org/10.4236/psych.2014.519212

[14] Rorschach, H. (1921) Psychodiagnostik Talfen. Huber, Bern.

[15] Biasi, V. and Bonaiuto, P. (2014) Negative Emotions and Defence Mechanisms in Obese People. Psychology, 5, 19791988. http://dx.doi.org/10.4236/psych.2014.518201

[16] Eysenck, H.J. (1959) Maudsley Personality Inventory. University of London Press, London.

[17] Spielberger, C.D., Gorsuch, R.L. and Lushene, R.E. (1970) Manual for the State-Trait Anxiety Inventory. Consulting 
Psychologists Press, Palo Alto.

[18] Hyun, J.K., Quinn, B.C., Madon, T. and Lustig, S. (2006) Graduate Student Mental Health: Needs Assessment and Utilization of Counseling Services. Journal of College Student Development, 47, 247-266. http://dx.doi.org/10.1353/csd.2006.0030

[19] Russell, J., Thomson, G. and Rosenthal, D. (2008) International Student Use of University Health and Counselling Services. The International Journal of Higher Education and Educational Planning, 56, 59-75. http://dx.doi.org/10.1007/s10734-007-9089-x

[20] Samuolis, J. and Griffin, K.W. (2014) Identity Distress and Negative Affect in College Students. Identity: An International Journal of Theory and Research, 14, 246-254. http://dx.doi.org/10.1080/15283488.2014.944694

[21] Biasi, V., Mallia, L., Menozzi, F. and Patrizi, N. (2015) Adaptive Functioning and Behavioral, Emotional and Social Problems of Italian University Students: Indications for the University Counseling Services. Paper to Be Presented at the 6th World Conference on Psychology, Counselling and Guidance, Antalya. www.sciencedirect.com 